\section{Congenital innervation dysgenesis syndrome (CID)/ congenital cranial dysinnervation disorders (CCDDs)}

\begin{abstract}
Congenital loss of innervation to the extraocular muscles (EOMs) can have a profound effect on the target muscle. This has been well recognised in Duane's retraction syndrome. However, it has been less emphasised in other congenital oculo-motor disorders. Such congenital ocular motor defects have been expanded to include DRS, congenital fibrosis of EOMs, monocular elevation defect, Möbius syndrome, as well as several other non-ocular muscles supplied by cranial nerves such as facial muscles. Such loss of innervation to motor muscles can be unified as a defined clinical entity, which can be labelled as congenital innervation dysgenesis syndrome or CID for short. CID may also affect other muscles supplied by nerves other than the cranial nerves and may be sensory as well as motor.
\end{abstract}

Eye (2011) 25, 1251-1261; doi:10.1038/eye.2011.38; published online 1 July 2011

Keywords: congenital innervation disorder; congenital innervation dysgenesis (CID); congenital cranial dysinnervation disorder (CCDD); congenital ocular motility defects; congenital fibrosis of extra-ocular muscles (CFEOM); Duane's syndrome

\section{Introduction}

For some time, congenital fibrosis syndrome of the extra-ocular muscles (CFEOMs) was considered to be of primary muscle pathology. However, evidence from multiple sources suggests that it is a neurological disorder rather than primary muscle pathology. This puts CFEOM in the category of other congenital ocular muscle disorders, which have a neurological basis, such as Duane's retraction syndrome (DRS), monocular elevation deficiency (MED) and Möbius syndrome. Nowadays, many investigators suggest unifying all these various congenital oculo-motor disorders into one entity. This entity may include abnormalities in innervation affecting cranial nerves and beyond, motor and may be sensory. For such a collection of congenital innervation disorders, cranial or otherwise, the term congenital innervation dysgenesis syndrome (CID) seems appropriate.

Congenital extra-ocular muscles disordersCongenital fibrosis syndrome of the EOMs

CFEOMs are characterised by variable impairment of horizontal and/or vertical eye movements and ptosis. It can be unilateral or bilateral, with the bilateral form being more common. Additional features include divergent strabismus and abnormal head position, especially chin elevation, ${ }^{1-5}$ see Figure 1. Attempts at defining subgroups for CFEOM have been made, ${ }^{6-9}$ but considerable overlap and intrafamilial variability exists.

Congenital fibrosis syndrome has traditionally been considered a primary muscle disorder. Ocular motility restrictions correlate with muscle hypoplasia, displaced scleral insertions, and an abnormal muscle substructure. Histopathologically, this condition is characterised by degenerative muscle changes and replacement of muscle fibres with fibrous tissue. ${ }^{2,6,7}$
Department of Opthalmology, Milton Keynes Hospital NHS FT, Milton Keynes, Bucks, UK

Correspondence: AA Assaf, Milton Keynes Hospital NHS FT, Standing Way, Milton Keynes, Bucks, MK5 5LD, UK

Tel: + 4401908243416 ; Fax: + 4401908243416 E-mail: a3assaf@

btinternet.com

Received: 15 December 2010

Accepted in revised form: 31 January 2011 Published online: 1 July 2011 


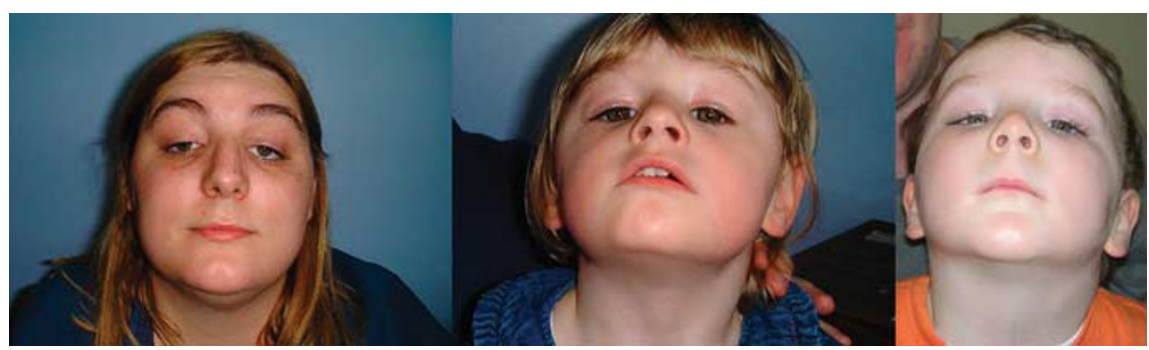

Figure 1 A mother and two children with CFEOM. This condition is usually sporadic and inherited in an autosomal dominant manner. However, in areas of the world where consanguineous marriages are common, autosomal recessive inheritance is more common.
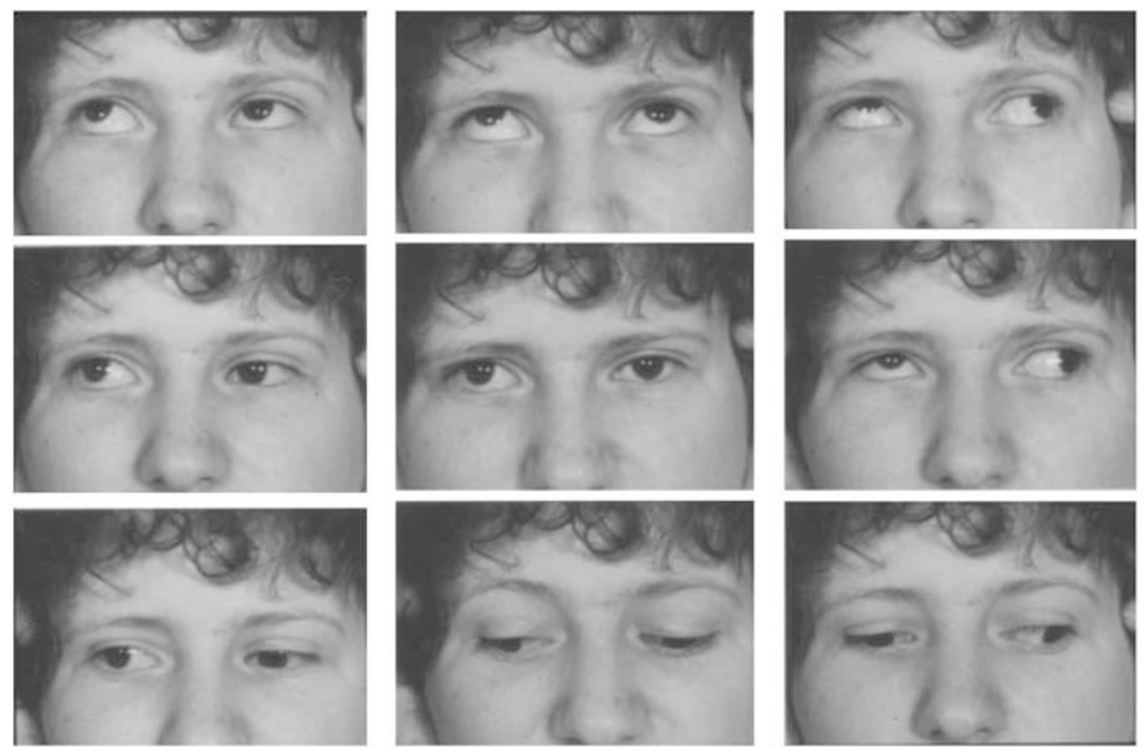

Figure 2 A patient with bilateral Duane's syndrome. ${ }^{16}$

Recently, CFEOM has been accepted to be of neurogenic origin rather than primary muscle pathology. Such congenital loss on innervation is associated with secondary muscle changes resulting in the clinical and histological picture seen in CFEOM, see under section 'Evidence for neurogenic aetiology of CFEOM' for details.

\section{Duane's syndrome}

DRS/Stilling-Turk syndrome, is another congenital nonprogressive ocular motility defect. It was first described by Stilling ${ }^{10}$ and Turk ${ }^{11}$. The syndrome is characterised by limitation or absence of abduction and/or adduction of the eyes. There is also retraction of the globe and narrowing of the palpebral fissure on adduction, which is often associated with elevation or depression of the globes. When abduction is attempted, one often finds widening of the palpebral fissure. Duane ${ }^{12}$ emphasised that retraction of the adducted involved eye is an essential feature of this syndrome.
In humans, pathological studies of DRS have provided clear evidence that innervational deficiencies can cause fibrotic muscle changes. Most cases are due to innervational defects, which correlate with aplasia of the sixth nerve nucleus and the VI cranial nerve itself. ${ }^{13,14}$ In DRS innervation of the lateral rectus is provided by the oculomotor nerve causing the pathognomonic co-contraction of the medial and lateral recti with globe retraction on adduction, Figure 2. Additionally, synkinesis phenomena seen in ophthalmology, such as eyelid elevation on attempted abduction have a similar physiological basis. ${ }^{15}$

The evidence for neurogenic aetiology for DRS was first derived from co-contraction elicited by electrophysiological studies. ${ }^{17,18}$ Additionally, the association of DRS with synkinesis phenomena such as Marcus Gunn jaw-winking have added further evidence. ${ }^{19}$ Further evidence has been derived from pathological studies. ${ }^{14,20}$ Recent advances in the imaging technology have made it easier to detect such subtle anatomical changes. ${ }^{21}$ 


\section{MED (double elevator palsy)}

MED or double elevator palsy is characterised by unilateral loss of elevation in all directions of gaze. This may be caused by restrictive or paretic causes and may be congenital or acquired. The term 'double elevator palsy' has now abandoned for the more descriptive the term of MED. In neurogenic cases, combined palsy of the inferior oblique and superior rectus muscles is unlikely; paresis of the superior rectus muscle alone is sufficient to produce the clinical picture. MED has also been recognised to be associated with disorders of innervation beside that of anatomical abnormalities. This has been observed in acquired paralysis resulting in MED. ${ }^{22,23}$ A significant number of patients with congenital MED are associated with synkinesis phenomena such as Marcus Gunn jaw-winking. ${ }^{24,25}$ Additionally, Olson and Scott ${ }^{25}$ found dissociated vertical deviation was present in $29 \%$ of MED patients, perhaps suggesting innervational rather than anatomical aetiology.

\section{Möbius syndrome}

Möbius syndrome is a heterogeneous clinical disorder, which includes congenital facial palsy with impairment of ocular abduction. The wide clinical spectrum and multiple areas of brainstem involvement in patients with Möbius syndrome have led to an early understanding that Möbius syndrome is a developmental disorder of the brainstem rather than an isolated cranial nerve developmental disorder.

The ocular motility disturbances in Möbius syndrome are frequently bizarre and asymmetrical, resembling more of a congenital fibrosis pattern than cranial nerve palsies. ${ }^{26}$ In a study of 37 patients with facial paresis by Verzijl et al, ${ }^{27}$ 97\% had bilateral and 3\% had unilateral ocular abduction weakness. Further analysis showed isolated abducens nerve palsy in $9 \%$, a conjugate horizontal gaze paresis in $48 \%$, features of DRS in $34 \%$, and congenital fibrosis of the extraocular muscles in $9 \%$.

\section{Evidence for neurogenic aetiology of CFEOM}

Recent evidence has suggested that normal intra-uterine development of the innervation of the extra-ocular muscles (EOMs) is of critical importance for normal development of these muscles themselves. ${ }^{28}$ Preservation of normal muscle fibre anatomy requires normal patterns of innervation, thus CID of EOMs can result in abnormal muscle structure, which depends on the stage and the extent of such innervational defects. Moreover, experimental denervation of extraocular muscles by ocular motor nerve sectioning, for instance, produces histological changes, which resemble primary ocular myopathies. ${ }^{29,30}$ Histological examination may therefore be unreliable in distinguishing neurogenic from myopathic ocular muscle weakness.

Co-contraction phenomenon resulting in globe retraction has also been described in patients with CFEOM. Cibis ${ }^{31}$ appears to be the first to describe an association between CFEOM and co-contraction in a family with three patients using electromyographic evidence. Later, this co-contraction phenomenon was also described by Assaf ${ }^{4,5}$ (Figure 3).

In another case report, Simonsz et $a l^{32}$ found that normal contraction of the superior recti using succinylcholine in a patient with CFEOM, which was only compatible with a supranuclear or mis-directional cause. Brodsky et $a l^{33}$ described a case of innervational misdirection in a patient with CFEOM. Furthermore, electro-myographic studies in Möbius syndrome, the ocular motility disturbances of which resemble that of CFEOM than a muscle palsy, ${ }^{26}$ have shown patterns suggesting of supra-nuclear origin. ${ }^{34,35}$

Patients with CFEOM commonly have variable angle strabismus. ${ }^{4,5}$ Purely mechanical factors appear
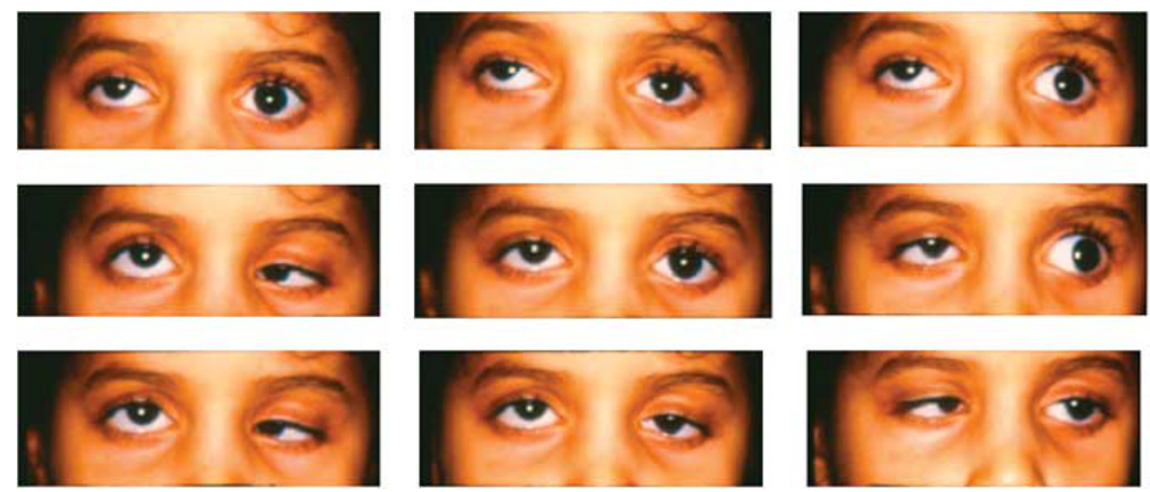

Figure 3 A patient with bilateral CFEOM. Notice the retraction of the globe on adduction and the widening of the palpebral fissure on abduction in left eye. Without the vertical gaze abnormalities, this patient would be diagnosed as Duane's syndrome. ${ }^{4-5}$ 
insufficient to explain this variability, which more likely reflects innervational disturbances. Furthermore, the degree of limitation of ocular movements in some patients did not always correlate with the degree of tightness of the agonist or antagonist muscle, as indicated by the intraoperative forced duction test. ${ }^{4,5,31}$

Nystagmus is another indicator of central ocular motor disturbance in cases of CFEOM. Cases of nystagmus have been described to be associated in patients of CFEOM. ${ }^{4,5,9}$ Results of neuro-imaging have only been reported in a relatively small numbers of patients with CFEOM. Abnormalities such as cerebellar hypoplasia ${ }^{4,5}$ and asymmetrical ventricular size ${ }^{9}$ further hint at the possibility of brain malformation.

Based on the above, Assaf ${ }^{4,5}$ argued that cases of CFEOM have neurogenic aetiology similar to that of DRS but involving the III cranial nerve complex. Thus, CFEOM may share anatomical similarities with DRS, but results from CID of the III cranial nerve complex. Ptosis, loss of up- and downgaze, pupilloplegia, and all the findings discussed above in patients with CFEOM would suggest the involvement of the third nerve nuclei and the supranuclear structures involved in the central control of vertical eye movements. In humans, burst neurons for vertical gaze are located in the rostral interstitial nucleus of the medial longitudinal fascicle. ${ }^{36}$ Lesions of this nucleus or its efferents to the oculomotor subnuclei cause vertical eye movement restrictions with variable involvement of up- and downward gaze. The nearby nucleus of Cajal participates in the control of vertical pursuit movements, mediates vestibular input to the oculomotor nuclei, and functions as a neural integrator of vertical and torsional gaze. The anatomical proximity of these structures suggests a shared vulnerability to congenital malformations, which may involve the nuclei themselves and their connections. The complexity of the functional interactions between supranuclear structures and the ocular motor nerves may account for the highly variable expressions of vertical and horizontal gaze abnormalities in CFEOM., ${ }^{4,5}$

Such innervational abnormalities are compounded by secondary changes in muscle structure. Therefore, mechanical factors could contribute to some of the motility disturbances associated with CFEOM. Tightness of the inferior recti, for instance, may cause convergence on attempted upgaze in a similar fashion as the increased tension of co-contracting horizontal recti causes up-and downshoot phenomena in DRS, Figure 4.

To confirm the above findings, Engle et $a l^{37}$ described an oculomotor nerve and muscle abnormalities in a case of CFEOM. The investigators described complete absence of the superior division of the III cranial nerve in an autopsy of a patient with CFEOM.

The studies proposing a neurogenic aetiology for CFEOM are summarised in Table 1.

It is accepted that DRS and MED or double elevator palsy are due to CID of the EOMs. CID of the lateral rectus muscle, as seen in DRS, can result in abnormal muscle structure, loss of muscle function, co-contraction, and contraction against a tight muscle. Furthermore, it

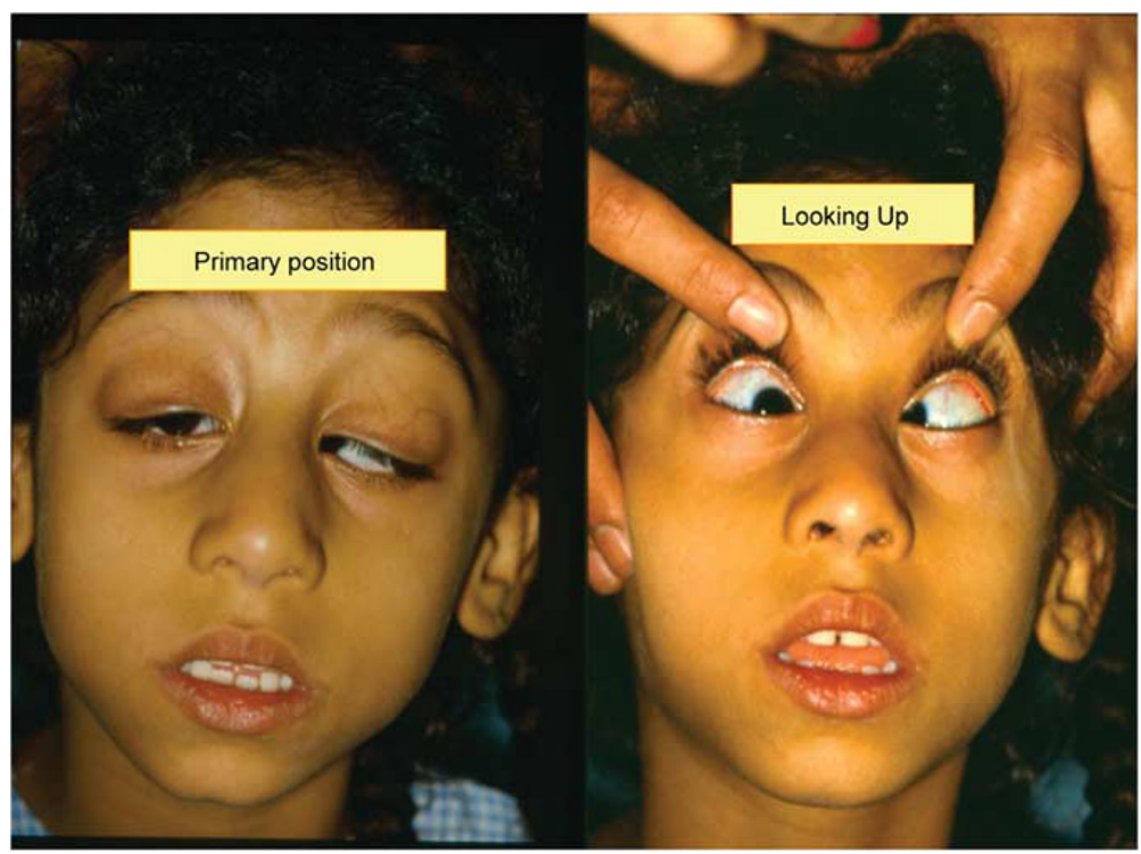

Figure 4 A patient with CFEOM. Notice the adduction of both eyes on attempted elevation. 
Table 1 Studies suggested that CFEOM might be of neurogenic in aetiology

\begin{tabular}{|c|c|c|}
\hline Author & Year & Clinical study-number of patients \\
\hline Cibis $^{31}$ & 1984 & 3 Patients using electromyographic evidence \\
\hline Simonsz ${ }^{32}$ & 1988 & 1 Patient using pharmacological evidence \\
\hline Brodsky et $a l^{33}$ & 1989 & 1 Patient, innervational misdirection \\
\hline Assaf $^{4,5}$ & 1992, 1997 & $8^{4}(9)^{5}$ Patients using clinical evidence and radiological findings \\
\hline Gillies et $a l^{9}$ & 1995 & 5 Patients, radiological findings \\
\hline Engle et $a l^{37}$ & 1997 & 1 Autopsy and 2 muscle biopsies, anatomical findings \\
\hline
\end{tabular}

Table 2 Clinical classification of the ocular motor CID syndrome depending of the gaze affected ${ }^{38}$

\begin{tabular}{|c|c|c|c|}
\hline & Type A & Type B & Type C \\
\hline Type I: & IA & IB & IC \\
\hline purely horizontal & Add-Duane type B & ABd-Duane type A & Both-Duane type C9 \\
\hline Type II: & IIA & IIB & IIC \\
\hline purely vertical & $\mathrm{Up}$-commonest & Down & Both-up and down \\
\hline Type III: & IIIA & IIIB & IIIC \\
\hline horizontal + vertical & Elevation + horizontal & Depression + horizontal & Elevation and depression + horizontal \\
\hline
\end{tabular}

has been suggested that Möbius syndrome is supranuclear in origin. ${ }^{34,35}$ Similarly, in view of the above discussion CFEOM can be added to this category of CID, in this instance involving the III cranial nerve and its supra-nuclear complex. These innervational defects affect the vertical, and to a lesser degree the horizontal, eye movements.

\section{Congenital innervation disorders syndromes CID syndrome}

For such congenital ocular motor abnormalities associated with congenital loss/abnormality of innervation described above, Assaf ${ }^{38}$ proposed the term of CID syndrome. He suggested the features of this syndrome to include:

- Congenital defect in the innervation EOMs.

- Present since birth, and non-progressive.

- Unilateral or bilateral.

- Findings are not explained by purely isolated oculomotor nerve palsy/palsies.

- Anatomical muscle changes, including tight muscle.

- Can be associated with synkinesis phenomena and/or co-contraction.

- Abnormal head posture is common.

Assaf in his above publication proposed to integrate CFEOM, DRS, and MED into one category called CID and proposed a clinical classification for such conditions (Table 2).

\section{Congenital cranial dysinnervation disorders (CCDDs)}

Later, Gutowski et al ${ }^{39}$ proposed the term of CCDDs. They define these disorders include CFEOM, congenital ptosis, Duane's syndrome, Duane radial ray syndrome, horizontal gaze palsy with progressive scoliosis (HGPPS), and Möbius syndrome. The CCDDs would also encompass developmental disorders of non-ocular cranial nerves, such as congenital familial facial weakness. They summarised the features of the CCDDs as follows:

- Congenital, non-progressive abnormalities of cranial musculature that result from developmental abnormalities of one or more cranial nerves with primary or secondary muscle dysinnervation.

- Primary may result from absence of normal muscle innervation. Secondary may occur from aberrant muscle innervation during development by branches of other nerves.

- May be associated with secondary muscle pathology and/or other orbital and bony structural abnormalities.

- Predominantly vertical ocular motility defects are likely to result from abnormalities in development of oculomotor and trochlear nerves and/or nuclei (CFEOM variants and congenital ptosis).

- Predominantly horizontal ocular motility defects are likely to result from abnormalities in the development of the abducens nerve and/or nucleus (Duane's syndrome and HGPPS).

- Predominately facial weakness is likely to result from abnormal development of facial nerve and/or nucleus, 
sometimes with associated ocular motor abnormalities (congenital facial weakness and Möbius syndrome).

The investigators suggested that in addition to DRS and CFEOM, it is also possible that familial HGPPS and at least some forms of Möbius syndrome result from developmental dysinnervation. ${ }^{40}$ Traboulsi $^{41}$ suggested that CCDDs might involve cranial sensory as well as motor nerves, Figure 5. Recently, Kolling et $a l^{42}$ indicated congenital Brown's syndrome is caused by missing fourth cranial nerve in some cases, which put it in the category of congenital dysinnervation. This fits into Assaf assertion that CID can occur in congenital nonprogressive ocular motility disorders not explained by purely isolated oculo-motor nerve palsy. ${ }^{38}$

The above description of CCDDs is more or less the same as the CID described by Assaf a few years earlier. To CID the investigators of CCDDs added ptosis, Möbius syndrome, and HGPPS. However, it is well known that ptosis is a feature of CFEOM (see definition of the CFEOM above) and Möbius syndrome has been known to have neural aetiology for some time. ${ }^{34,35}$ Moreover, in his original paper on the $\mathrm{CID}^{38}$ Assaf alluded to Möbius syndrome, quoting it as supporting evidence for the CID syndrome. Additionally, the HGPPS is not a CCDD per say; it associated with scoliosis because of innervational disorder of the muscles of the spine. Thus, it is a case of CID involving the ocular and spinal muscles.

Furthermore, although the HGPPS is genetic it is progressive and associated with progressive ophthalmoplegia and progressive scoliosis, which is against the definition of CCDDs and are defined as non-progressive.

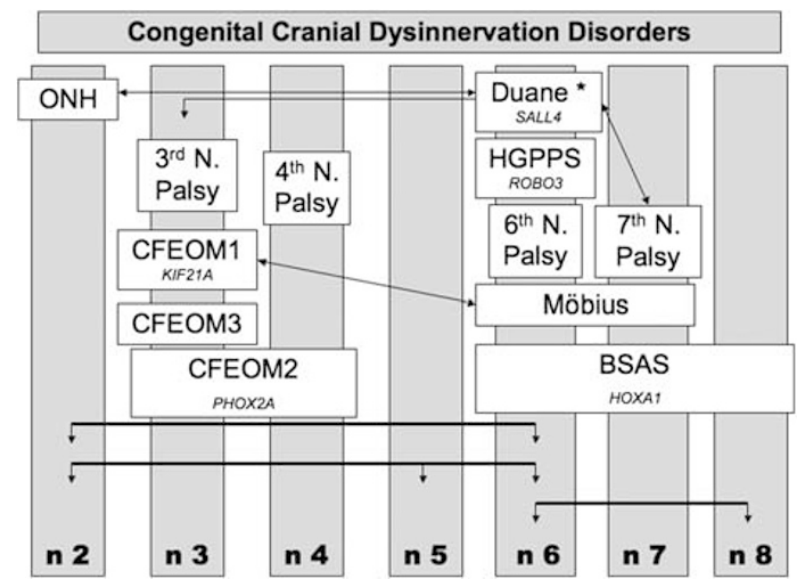

Figure 5 Clinical syndromes in CCDDs and corresponding cranial nerves. Responsible gene names are given in italics. The three lines and arrows in the bottom part of the illustration indicate associations in individual case reports or minority of patients with known syndromes. All conditions listed in this diagram are congenital. *Mobius' syndrome can also involve cranial nerves 9 and 12 (see Traboulsi). ${ }^{41}$
Therefore, CID and CCDDs syndromes are essentially the same. The term CID rather than CDDDs might be preferable for the following reasons:

- This was the original description of the congenital dysinnervation syndrome in 1998, several years preceding that of the CCDDs.

- CID may occur beyond the cranial motor nerves and may occur in other parts of the body, thus a more general and encompassing name of CID seems more appropriate than CCDDs, which localise it to cranial nerves for no logical reason.

CID affects various cranial motor, and perhaps sensory, nerves resulting in a variety of clinical pictures. It may also affect motor and perhaps non-motor innervations in other parts of the body beyond the cranial nerves. The description of the effects in such pathology is beyond the scope of an ophthalmologist.

\section{Genetics of congenital strabismus}

Congenital strabismus in humans can result from mutations in a number of genes, including $P H O X 2 A,{ }^{43}$ SALL ${ }^{44,45} \mathrm{HOXA1}^{46} \mathrm{ROBO3}^{47}$ and KIF $21 A^{48}$ that are essential to the normal development of brainstem motor neurons or axons. The genetics of CID ocular motility defects affecting cranial nerves (CCDDs) have been studied extensively by various investigators particularly Dr Engel and collaborators at Harvard. These were found to arise from mutations in any of the above of genes. The PHOX2A and KIF21A genes appear to affect development of the midbrain oculomotor and/or trochlear axis, and mutations result in abnormalities of both vertical and horizontal gaze. On the other hand SALL4, ROBO3, and HOXA1 affect development of the pontine abducens axis, and mutations result in primary abnormalities of horizontal gaze. The underlying gene defects lead to errors at various developmental stage and locations along the developing neuroaxis, including predicted errors in hindbrain segmentation (HOXA1), motoneuron specification $(P H O X 2 A)$, and axon targeting (CFEOM1, ROBO3). ${ }^{49}$

\section{Congenital fibrosis syndrome of the EOM}

To date, three genetic CFEOMs loci have been identified and three clinical phenotypes have been delineated, CFEOM 1-3.

CFEOM1 has autosomal dominant inheritance with full penetrance and minimal variation in expression has been mapped to the centromeric region of chromosome $12 .^{50-52}$ It has also now been demonstrated that CFEOMI results from heterozygous mutations in the KIF21A gene encoding a kinesin motor protein. ${ }^{48}$ 
CFEOM2 is an autosomal recessive disorder, mapped to chromosome $11 \mathrm{~g} 13.1 .711 . .^{53,54}$ Later, this was shown to result from mutations in the $\mathrm{PHOX} 2 \mathrm{~A}$ gene. ${ }^{44} \mathrm{PHOX} 2 \mathrm{~A}$ and its close relative, $P H O X 2 B$, are homeodomain transcription factor genes with identical homeodomains. They have similar expression patterns restricted to several classes of differentiating neurons in the central and peripheral nervous system. ${ }^{55,56} \mathrm{PHOX} 2 \mathrm{~A}$ is expressed at E9 in the proliferating oculomotor and trochlear motor neuron precursors in mice ${ }^{56}$ supporting the hypothesis that CFEOM2 results from abnormal development of the oculomotor and, possibly, trochlear nerves. $^{43}$

CFEOM3 is an autosomal dominant disorder with variable expression and probably incomplete penetrance. The gene in CFEOM3 maps to markers on 16p24.2g24.3. ${ }^{57,58}$ The CFEOM3 pedigrees are typically a dominant trait with wider phenotypic variability than found in CFEOM1 and CFEOM2. In some families all affected individuals have CFEOM $3,{ }^{9,57}$ and in other families some affected individuals have CFEOM3 and some have CFEOM1. ${ }^{57}$

\section{Duane's syndrome}

Genetic studies of autosomal dominant DRS led to the identification of CHN1 as a DRS gene. ${ }^{59,60}$ It is suggested that human CHN1 mutations alter the development of abducens and, to a lesser extent, oculomotor axons. ${ }^{60}$

\section{DRS without systemic associations}

To date, only one genetic locus has been mapped. The DURS2 locus on chromosome 2q31 was established by linkage analysis of a large dominant DRS pedigree. ${ }^{61}$ The DURS1 locus is assumed to reflect disruption of a gene for isolated DRS and is defined by cytogenetic abnormalities of $8 \mathrm{q} 12.2-8 \mathrm{q} 21.2{ }^{62-64}$ The chromosome 8 break point was found to occur between exons 1 and 2 of a carboxypeptidase gene, CPA6 (CPAH), which is hypothesised to have a role in peptide processing in the brain. ${ }^{64}$

\section{DRS with systemic associations}

Of the various malformation syndromes, associated with DRS, Duane radial ray syndrome has been genetically mapped. It is inherited as dominant and with incomplete penetrance. This condition has been mapped to chromosome $20^{44}$ and results from heterozygous nonsense frame shift, and deletion mutations in SALL4. ${ }^{44,45}$ The SALL4 gene has also been implicated in DRS associated with Holt-Oram and acro-renal-ocular syndromes. ${ }^{65}$ Additionally, linkage analysis of pedigrees with Bosley-Salih-Alorainy syndrome (a condition with Bilateral DRS and systemic findings) localised the gene to chromosome 7p15.2, encompassing the HOXA gene cluster. $^{46}$

\section{Möbius syndrome}

\section{Most cases are sporadic}

Three Möbius syndrome loci have been mapped: MBS1 to $13 \mathrm{q} 12.2-\mathrm{q} 13,{ }^{66} \mathrm{MBS} 2$ to $3 \mathrm{q} 21-\mathrm{q} 22,{ }^{67}$ and MBS 3 to $10 \mathrm{q} 21.3-\mathrm{q} 22.1 .^{68}$

Tischfield et $a l^{46}$ reported horizontal gaze palsy and facial weakness in consanguineous patients with recessive HOXA1 mutations. However, in another pedigree study by Dumars et $a l^{69}$ no mutations were detected in the genes PHOX2A, HOXA1, and KIF21A.

\section{Horizontal gaze palsy with progressive scoliosis}

Horizontal gaze palsy with progressive scoliosis maps to chromosome $11^{70}$ and results from homozygous or compound heterozygous mutations in $R O B 03 .{ }^{47,71}$ The nature and distribution of these mutations suggest that horizontal gaze palsy with progressive scoliosis results from the complete loss of $R O B 03$ function.

\section{Neural imaging in congenital innervational disorders}

Neuroanatomic abnormalities are often missed on routine intracranial MR imaging, which frequently shows no overt structural malformations of the brain. However, the advent of high-resolution images (MRI) has resulted in better visualisation of neural structures. Thus, it became possible to show hypoplasia or absence of the oculomotor nerves and involved extraocular muscles in patients with CID, see Figure $6 .{ }^{72}$ Such changes included absence or hypoplasia of various oculo-motor nerves, hypoplasia and reduction in the size of the EOMs and even bony orbital changes. ${ }^{73-76}$

\section{Congenital fibrosis syndrome of the EOM}

Assaf $^{4,5}$ documented neurological findings in CFEOM patients using the CT and MRI scans. In his study of eight patients with CFEOM, in one case the CT-scan indicated agenesis of superior rectus in both eyes. Another case had mental retardation with delayed milestones of development with the MRI suggesting possible cerebellar hypoplasia.

Another early study on radiological imaging of CFEOM patients using CT scan was conducted by Gillies et al. ${ }^{9}$ The investigators studied five patients with CFEOM and some normal family members. They have documented reduction in size of the extraocular muscles, particularly the superior recti with intracranial ventricular asymmetry in three of five patients examined, 


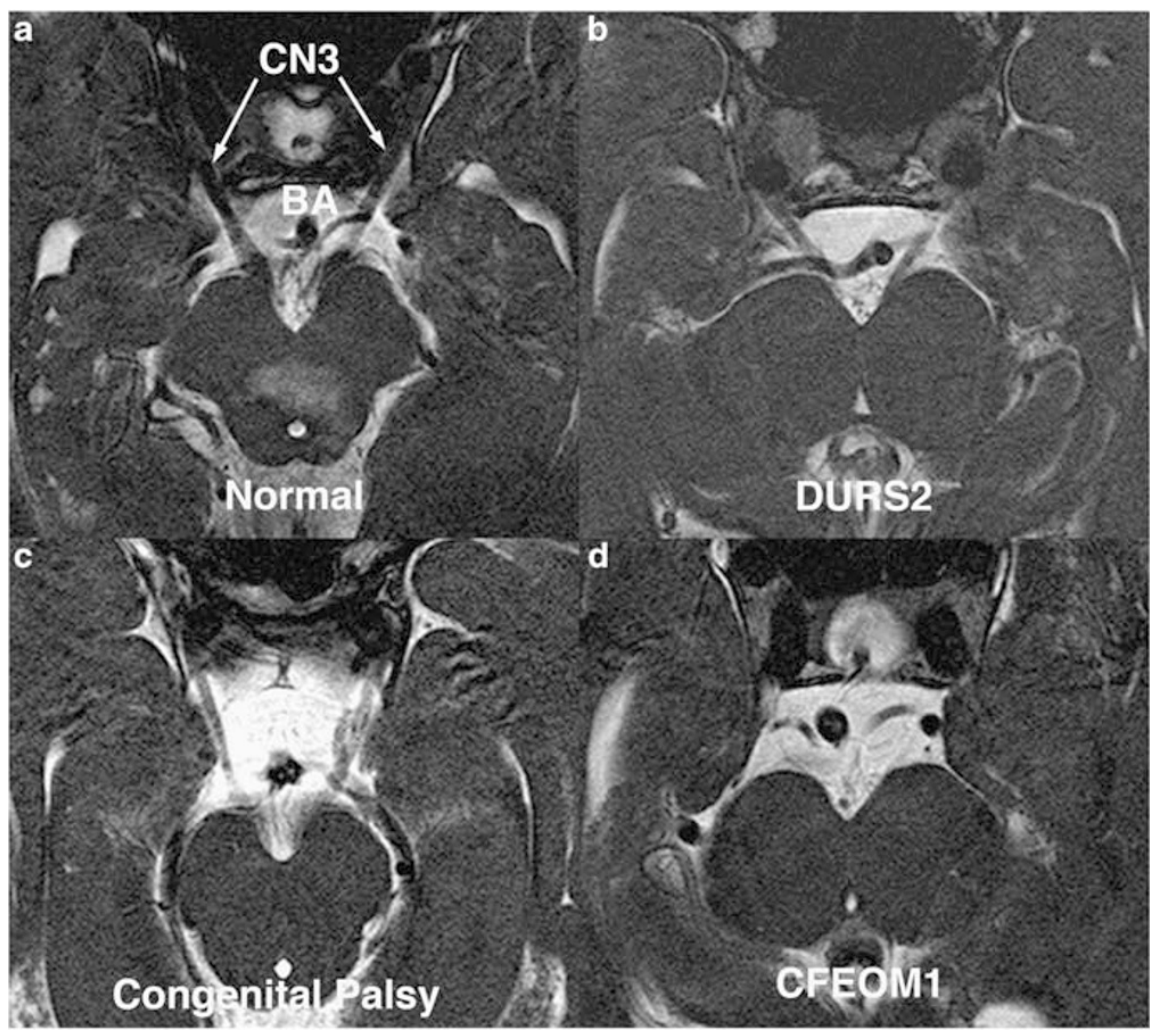

Figure 6 Fiesta MRI in some CCDDs entities demonstrating hypoplasia of the sub-arachoind oculomotor nerve (CN3). (a) Normal subject. (b) DRS linked to chromosome 2 (DURS2). (c) Congenital oculomotor palsy. (d) Congenital fibrosis of the EOMs type I (CFEOM I) (see Demer). ${ }^{72}$

and abnormality in shape of the eye globes in two patients.

Several studies have documented abnormalities in EOMs or their nerve supply in cases of CFEOM using high-resolution MRI studies. Such studies showed hypoplasia of the oculomotor nerve and EOMs, ${ }^{77-80}$ sometimes with absence of the abducens nerve. ${ }^{80}$

These imaging studies confirmed the proposed aetiology of CFEOM being of neurogenic with secondary muscle changes, rather than primary muscle pathology.

\section{Duane's syndrome}

Similarly, several studies using high-resolution MRI exhibited absence or hypoplasia of CN6 in the orbit or brainstem regions, ${ }^{59,81-85}$ often with mild hypoplasia and apparent misdirection of $\mathrm{CN} 3$ to the lateral rectus muscle. High-resolution MRI can non-invasively demonstrate LR muscle size and distinguish DRS from chronic abducens palsy in uncertain cases. The LR muscle in abducens palsy exhibits profound atrophy. However, the sparing of the LR in DRS from denervation atrophy despite absence of normal abducens innervation suggests existence of alternative LR innervation. ${ }^{82}$ It can also be used to distinguish DRS from lateral rectus muscle palsy in paediatric patients. ${ }^{84}$ However, the CN6 can be present in some patients with Duane's type II and III. ${ }^{85}$

\section{Möbius syndrome}

Studies in patients with Möbius syndrome using high-resolution image studies demonstrated brain stem hypoplasia in the region of the sixth and the seventh nerve complexes with or without other posterior fossa abnormalities. ${ }^{66,86-88}$ Pedraza et $a l^{86}$ MRI study on patients with Möbius syndrome also showed marked hypoplasia of extraocular muscles and intraorbital motor nerves.

Such radiologic findings supported the notion that Möbius syndrome is part of a more complex congenital anomaly of the posterior fossa and suggests that the diagnosis of Möbius syndrome correlates with the clinical and neurophysiologic findings.

\section{Conclusions}

The understanding of congenital strabismus has been significantly enhanced over the past 2 decades. The grounds were already laid by the works of various 
investigators, which culminated in Dr Engle group papers in 1997 on finding anatomical evidence for congenital dysinnervation in CFEOM (please see Table 2). Assaf proposed to join several congenital innervational ocular motility disorders into one syndrome and he proposed the name of the CID. Later, Gutowski et $a^{39}$ added to the CID isolated ptosis (which is part of the CFEOM) and facial diplegia (which is part of Möbius syndrome) and HGPPS and introduced the term CCDDs. This will not be the end of story since no doubt CID occurs in the eye muscles, facial muscles and beyond.

Beside the above two exciting areas developments occurred in this topic. First, significant advances occurred in the understanding genetics of congenital strabismus, which opened the door on the development of some aspects of the developing brain. Second, the introduction of high-resolution MRI allowed the study of cranial nerves courses and supplied muscles in more details. Several studies by various investigators were conducted in this field, which confirmed the clinical notions introduced earlier by various investigators on the aetiology of congenital strabismus.

\section{Conflict of interest}

The author declares no conflict of interest.

\section{References}

1 Crawford JS. Congenital fibrosis syndrome. Can J Ophthalmol 1970; 5: 331-336.

2 Apt L, Axelrod RN. Generalized fibrosis of the extraocular muscles. Am J Ophthalmol 1978; 85: 822-829.

3 Allen SM. General fibrosis syndrome: keeping it in the family. Br Orthopt J 1990; 47: 82-86.

4 Assaf A. Bilateral congenital disorders of vertical gaze: congenital muscle fibrosis or congenital neurogenic disorder?. Transaction of the 20th Meeting of the European Strabismological Association, Editor H Kaufman, Brussels May 1992; 249-254.

5 Assaf A. Bilateral congenital disorders of vertical gaze: congenital muscle fibrosis or congenital neurogenic disorder? Neuro-ophthalmology 1997; 17: 23-30.

6 Harley RD, Rodrigues MM, Crawford JS. Congenital fibrosis of the extraocular muscles. Trans Am Ophthalmol Soc 1978; 76: 197-226.

7 Harley RD, Rodrigues MM, Crawford JS. Congenital fibrosis of the extraocular muscles. J Pediatr Ophthalmol Strab 1978; 15: 346-358.

8 Khodadoust AA, Von Noorden GK. Bilateral vertical retraction syndrome. A family study. Arch Ophthalmol 1967; 78: 606-612.

9 Gillies WE, Harris AJ, Brooks AMV, Rivers MR. Congenital fibrosis of the extraocular muscles. A new group of dominantly inherited ocular fibrosis with radiologic findings. Ophthalmology 1995; 102: 607-612.
10 Stilling J. Untersuchungen uber die Entstenhung der Kurzsichtigkeit Wiesbaden (Germany), JF Bergmann, 1887, p 13.

11 Turk S. Uber Retractionsbewegungen des Auges. Dtsch Med Wochenschr 1896; 22: 199.

12 Duane A. Congenital deficiency of abduction associated with impairment of adduction, retraction movements, contraction of palpebral fissure and oblique movements of the eye. Arch Ophthalmol 1905; 34: 133-159.

13 Wilcox LM, Gitenger Jr JW, Breinin GM. Congenital adduction palsy \& synergestic divergence. Am J Ophthalmol 1981; 91: 1-7.

14 Miller NR, Kiel SM, Green WR, Clark AW. Unilateral Duane's retraction syndrome (type I). Arch Ophthalmol 1982; 100: 1468-1472.

15 Murray RI, Steven PSC. Congenital levator and lateral rectus muscle associated reflex. Neuro-Ophthalmology 1986; 6: 29-31.

16 Assaf A, Pope L. A family with bilateral Duane retraction syndrome, dominant inheritance and prominent systemic features. Annals Saudi Med 1990; 10: 313-318.

17 Hoyt WF, Nachtigaller H. Anomalies of ocular motor nerves. Neuroanatomic correlates of paradoxical innervation in Duane's syndrome and related ocular motor disorders. Am J Ophthalmol 1965; 60: 443-448.

18 Huber A. Electrophysiology of the retraction syndrome. Br J Ophthalmol 1974; 58: 293-300.

19 Isenberg S, Blechman B. Marcus Gunn jaw winking and Duane's retraction syndrome. J Pediatr Ophthalmol Strabismus 1983; 20: 235-237.

20 Hotchkiss MG, Miller NR, Clark AW, Green WR. Bilateral Duane's retraction syndrome. Arch Ophthalmol 1980; 98: 870-874.

21 Parsa CF, Grant E, Dillon W, du Lac S, Hoyt WF. Absence of abducent nerve in Duane syndrome verified by magnetic resonance imaging. Am J Ophthalmol 1998; 125: 399-401.

22 Jampel RS, Fells P. Monocular elevation paresis caused by central nervous system lesion. Arch Ophthalmol 1968; 80: 45-57.

23 Ford CS, Schwartze GM, Weaver RG, Troost BT. Monocular elevation paresis caused by an ipsilateral lesion. Neurology 1984; 34: 1264-1267.

24 Pratt SG, Beyer CK, Johnson CC. The Marcus Gunn phenomenon: a review of 71 cases. Ophthalmology 1984; 90: $27-30$.

25 Olson RJ, Scott WE. Dissociated phenomena in congenital monocular elevation deficiency. J Pediatr Ophthalmol Strab 1998; 2: 72-78.

26 Miller MT, Newlin A. Möbius sequence. In: Wright K, Spiegel P, Thompson L (eds) Handbook of Paediatric Eye and Systemic Disease 2006. Springer Science + Buisness, Media Inc.: Springer, pp 195-199.

27 Verzijl HT, van der Zwaag B, Cruysberg JR, Padberg GW. Mobius syndrome redefined: a syndrome of rhombencephalic maldevelopment. Neurology 2003; 61: 327-333.

28 Porter JD, Hauser KF. Survival of extraocular muscle in long term organotypic culture: differential influence of appropriate and inappropriate motor neurones. Dev Biol 1993; 160: 39-50.

29 Baker RS, Millett AJ, Young AB, Markesberg WR. Effects of chronic denervation on the histology of canine extra-ocular muscle. Invest Ophthalmol Vis Sci 1982; 22: 701-705.

30 Drachman DA, Wetzel N, Wasserman M, Naito H. Experimental denervation of the ocular muscles. A critique 
of the syndrome of 'ocular myopathy'. Arch Neurol 1969; 21: 170-183.

31 Cibis GW. Congenital familial external ophthalmolplegia with co-contraction. Ophth Paed Genet 1984; 4: 163-168.

32 Simonsz HJ, Kolling GH, van Dijk B, Kaufmann H. Lengthtension curves of human eye muscles during succinylcholine- induced contraction. Invest Ophthalmol Vis Sci 1988; 29: 1320-1330.

33 Brodsky MC, Pollock SC, Buckley EG. Neural misdirection in congenital ocular fibrosis syndrome: implications and pathogenesis. J Pediatr Ophthalmol Strab 1989; 26: 159-161.

34 Merz M, Wojtowicz S. The Möbius syndrome. Report of electromyographic examination in two cases. Am J Ophthalmol 1967; 63: 837-841.

35 Van Allen MW, Blodi FC. Neurologic aspects of Möbius syndrome. A case study with electromyography of the extra-ocular muscles. Neurology 1960; 10: 249-259.

36 Henn V, Butfner-Ennever JA, Flier K. The primate oculomotor system. I. Motoneurons. A synthesis of anatomical, physiological, and clinical data. Human Neurobiol 1982; 1: 77-85.

37 Engle EC, Goumnerov BC, McKeown CA, Schatz M, Johns DR, Porter JD et al. Oculomotor nerve and muscle abnormalities in congenital fibrosis of the extraocular muscles. Ann Neurol 1997; 41: 314-325.

38 Assaf A. Congenital innervation defect syndrome. In: Lennerstrand G (ed). Advances in Strabismology, Proceedings of the VIIIth International Strabismological Association. Maastricht: The Netherlands, September 1998, pp 158-161.

39 Gutowski NJ, Bosley TM, Engle EC. 110th ENMC International Workshop: the congenital cranial dysinnervation disorders (CCDDs). Naarden: The Netherlands, 25-27 October 2002; 13: 573-578.

40 Gutowski NJ, Ellard S. The congenital cranial dysinnervation disorders (CCDDs). Adv Clin Neurosci Rehabil 2005; 5: 8-10.

41 Traboulsi E. Congenital cranial dysinnervation disorders and more. J Am Acad Ped Ophthalmol Strab 2007; 11: 215-217.

42 Kolling G, Rohde S, Kress B. Congenital Brown's syndrome is caused by missing fourth cranial nerve in some cases. In: Presented at the 32nd Meeting of $f$ the European Strabismological Association, Munich, Germany; 7-10 September 2008.

43 Nakano M, Yamada K, Fain J, Sener EC, Selleck CJ, Awad $\mathrm{AH}$ et al. Homozygous mutations in ARIX(PHOX2A) result in congenital fibrosis of the extraocular muscles type 2 . Nat Genet 2001; 29: 315-320.

44 Al-Baradie R, Yamada K, St Hilaire C, Chan WM, Andrews $\mathrm{C}$, McIntosh $\mathrm{N}$ et al. Duane radial ray syndrome (Okihiro syndrome) maps to 20q13 and results from mutations in SALL4, a new member of the SAL family. Am J Hum Genet 2002; 71: 1195-1199.

45 Kohlhase J, Heinrich M, Schubert L, Liebers M, Kispert A, Laccone $\mathrm{F}$ et al. Okihiro syndrome is caused by SALL4 mutations. Hum Mol Genet 2002; 11: 2979-2987.

46 Tischfield MA, Bosley TM, Salih MA, Alorainy IA, Sener EC, Nester MJ et al. Homozygous HOXA1 mutations disrupt human brainstem, inner ear, cardiovascular and cognitive development. Nat Genet 2005; 37: 1035-1037.

47 Jen IC, Chan WM, Bosley TM, Wan J, Carr JR, Rüb U et al. Mutations in a human ROBO gene disrupt hindbrain axon pathway crossing and morphogenesis. Science 2004; 304: 1509-1513.
48 Yamada K, Andrews C, Chan WM, McKeown CA, Magli A, de Berardinis $\mathrm{T}$ et al. Heterozygous mutations of the kinesin KIF21A in congenital fibrosis of the extraocular muscles type 1 (CFEOM1). Nat Genet 2003; 35: 318-321.

49 Engle EC. Genetic basis of congenital strabismus. Arch Ophthalmol 2007; 125(2): 189-195.

50 Engle EC, Kunkel LM, Specht LA, Beggs AH. Mapping a gene for congenital fibrosis of the extraocular muscles to the centromcric region of chromosome 12. Nat Genet 1994; 7: 69-73.

51 Engle EC, Marondel I, Houtman WA, de Vries B, Loewenstein A, Lazar $\mathrm{M}$ et al. Congenital fibrosis of the extraocular muscles (autosomal dominant congenital external ophthalmoplegia): genetic homogeneity, linkage refinement, and physical mapping on chromosome 12 . Am Hum Genet 1995; 57: 1086-1094.

52 Uyama E, Yamada K, Kawano H, Chan WM, Andrews C, Yoshioka $\mathrm{M}$ et al. A Japanese family with FEOM 1-linked congenital fibrosis of the extraocular muscles type I (CFEOMI) associated with spinal canal stenosis and refinement of the FEOM critical region. Neuromuscul Disord 2003; 13: 472-476.

53 Engel EC, Johnson RH, Jabak MH, Assaf A, Hepler RS, Zwann $\mathrm{T}$ et al. Evidence for genetic heterogeneity among individuals with clinical diagnosis of congenital fibrosis of extraocular muscles. Am J Human Genet 1996; 59(4): 382.

54 Wang S, Zwaan J, Mullaney P, Jabak MH, Al-Awad A, Beggs $\mathrm{AH}$ et al. Congenital fibrosis of the extraocular muscles type 2, an inherited exotropic strabismus fixus, maps to distal 11g13. Am J Hum Genet 1998; 63: 517-525.

55 Tiveron MC, Hirsch MR, Brunet JF. The expression pattern of the transcription factor Phox 2 delineates synaptic pathways of the autonomic nervous system. J Neurosci 1996; 16: 7649-7660.

56 Pattyn A, Morin X, Cremer H, Goridis C, Brunet JF. Expression and interactions of the two closely related homeobox genes Phox2a and Phox $2 \mathrm{~b}$ during neurogenesis. Development 1997; 124: 4065-4075.

57 Mackey DA, Chan WM, Chan C, Gillies WE, Brooks AM, $\mathrm{O}^{\prime}$ Day $\mathrm{J}$ et al. Congenital fibrosis of the vertically acting extraocular muscles maps to the FEOM3 locus. Hum Genet 2002; 110: 510-512.

58 Doherty EJ, Macy ME, Wang SM, Dykeman CP, Melanson MT, Engle EC. CFEOM3: a new extraocular congenital fibrosis syndrome that maps to 16q24.2-q24.3. Invest Ophthalmol Vis Sci 1999; 40: 1687-1694.

59 Demer JL, Clark RA, Lim KH, Engle EC. Magnetic resonance imaging evidence for widespread orbital dysinnervation in dominant Duane's retraction syndrome linked to the DURS2 locus. Invest Ophthalmol Vis Sci 2007; 48: 194-202.

60 Miyake N, Chilton J, Psatha M, Cheng L, Andrews C, Chan WM et al. Human CHN1 mutations hyperactivate a2-chimaerin and cause Duane's retraction syndrome. Science 2008; 321: 839-843.

61 Appukuttan B, Gillanders E, Juo SH, Freas-Lutz D, Ott S, Sood $\mathrm{R}$ et al. Localization of a gene for Duane retraction syndrome to chromosome 2q31. Am J Hum Genet 1999; 65 1639-1646.

62 Vincent C, Kalatzis V, Compain S, Levilliers J, Slim R, Graia $\mathrm{F}$ et al. A proposed new contiguous gene syndrome on $8 \mathrm{q}$ consists of branchio-oto-renal (BOR) syndrome, Duane syndrome, a dominant form of hydrocephalus and trapeze aplasia: implications for the mapping of the BOR gene. Hum Mol Genet 1994; 3: 1859-1866. 
63 Calabrese G, Stuppia L, Morizio E, Guanciali Franchi P, Pompetti F, Mingarelli $\mathrm{R}$ et al. Detection of an insertion deletion of region 8q13-q21.2 in a patient with Duane syndrome: implications for mapping and cloning a Duane gene. Eur J Hum Genet 1998; 6: 187-193.

64 Pizzuti A, Calabrese G, Bozzali M, Telvi L, Morizio E, Guida V et al. A peptidase gene in chromosome $8 \mathrm{q}$ is disrupted by a balanced translocation in a Duane syndrome patient. Invest Ophthalmol Vis Sci 2002; 43: 3609-3612.

65 Kohlhase J, Schubert L, Liebers M, Rauch A, Becker K, Mohammed SN et al. Mutations at the SALL4 locus on chromosome 20 result in a range of clinically overlapping phenotypes, including Okihiro syndrome, Holt-Oram syndrome, acro-renalocular syndrome, and patients previously reported to represent thalidomide embryopathy. J Med Genet 2003; 40: 473-478.

66 Slee JJ, Smart RD, Viljoen DL. Deletion of chromosome 13 in Moebius syndrome. J Med Genet 1991; 28: 413-414.

67 Kremer H, Kuyt LP, van den Helm B, van Reen M, Leunissen JA, Hamel BC et al. Localization of a gene for Moebius syndrome to chromosome $3 \mathrm{q}$ by linkage analysis in a Dutch family. Hum Mol Genet 1996; 5: 1367-1371.

68 Verzijl HTFM, van den Helm B, Veldman B, Hamel BC, Kuyt LP, Padberg GW et al. A second gene for autosomal dominant Moebius syndrome is localized to chromosome 10q, in a Dutch family. Am J Hum Genet 1999; 65: 752-756.

69 Dumars S, Andrews C, Chan WM, Engle EC, Demer JL. Magnetic resonance imaging of the endophenotype of a novel familial Möbius like syndrome. J Am Acad Ped Ophthalmol Strab 2008; 12(4): 381-389.

70 Jen J, Coulin CJ, Bosley TM, Salih MA, Sabatti C, Nelson SF et al. Familial horizontal gaze palsy with progressive scoliosis maps to chromosome 11q23-25. Neurology 2002; 59: 432-435.

71 Chan WM, Traboulsi E, Arthur B, Friedman N, Andrews C, Engle E. Horizontal gaze palsy with progressive scoliosis can result from compound heterozygous mutations in ROB03. I Med Genet, 2006; 43: e11.

72 Demer JL. Neuroanatomical strabismus: congenital peripheral neuropathy: the congenital cranial dysinnervation disorders (CCDDs). In: Lorenz B, Brodsky MC (eds). Pediatric Ophthalmology, Neuro-Ophthalmology, Genetics Strabismus - New Concepts in Pathophysiology, Diagnosis, and Treatment. Springer: Vienna, Austria, 2010, Chapter 6, p 67.

73 Demer JL, Ortube MC, Engle EC, Neepa Thacker N. High-resolution magnetic resonance imaging demonstrates abnormalities of motor nerves and extraocular muscles in patients with neuropathic strabismus. J Am Acad Ped Ophthalmol Strab 2006; 10(2): 135-142.

74 Kau HC, Tsai CC, Ortube MC, Demer JL. High-resolution magnetic resonance imaging of the extraocular muscles and nerves demonstrates various etiologies of third nerve palsy. Am J Ophthalmol 2007; 143(2): 280-287.e2.

$75 \mathrm{Wu} \mathrm{TJ}$, Isenberg SJ, Demer JL. Magnetic resonance imaging demonstrates neuropathology in congenital inferior division oculomotor palsy. J Am Acad Ped Opthalmol Strab 2006; 10(5): 473-475.

76 Demer JL, Clark RA, Engle EC. Magnetic resonance imaging evidence for widespread orbital dysinnervation in congenital fibrosis of extraocular muscles due to mutations in KIF21A. Invest Ophthalmol Vis Sci 2005; 46: 530-539.

77 Kim JH, Hwang JM. Magnetic resonance imaging in three patients with congenital oculomotor nerve palsy. $\mathrm{Br} J$ Ophthalmol 2009; 93: 1266-1267.

78 Lim KH, Engle EC, Demer JL. Abnormalities of the oculomotor nerve in congenital fibrosis of the extraocular muscles and congenital oculomotor palsy. Invest Ophthalmol Vis Sci 2007; 48: 1601-1606.

79 Bosley TM, Oystreck DT, Robertson RL, al Awad A, Abu-Amero K, Engle EC. Neurological features of congenital fibrosis of the extraocular muscles type 2 with mutations in PHOX2A. Brain 2006; 129: 2363-2374.

$80 \mathrm{Kim}$ JH, Hwang JM. Hypoplastic oculomotor nerve and absent abducens nerve in congenital fibrosis syndrome and synergistic divergence with magnetic resonance imaging. Ophthalmology 2005; 112(4): 728-732.

81 Ozkurt H, Basak M, Oral Y, Ozkurt Y. Magnetic resonance imaging in Duane's retraction syndrome. J Pediatr Ophthalmol Strab 2003; 40: 19-22.

82 Kang NY, Demer JL. Comparison of orbital magnetic resonance imaging in Duane syndrome and abducens palsy. Am J Ophthalmol 2006; 142(5): 827-834.

83 Denis D, Dauletbekov D, Girard N. Duane retraction syndrome: type II with severe abducens nerve hypoplasia on magnetic resonance imaging. I Am Acad Ped Opthalmol Strab 2008; 12(1): 91-93.

$84 \mathrm{Kim} \mathrm{JH}$, Hwang JM. Usefulness of MR imaging in children without characteristic clinical findings of Duane's retraction syndrome. Am J Neuroradiol 2005; 26: 702-705.

$85 \mathrm{Kim} \mathrm{JH}$, Hwang JM. Presence of abducens nerve according to the type of Duane's retraction syndrome. Ophthalmology 2005; 112: 109-113.

86 Pedraza S, Gámez J, Rovira A, Zamora A, Grive E, Raguer $\mathrm{N}$ et al. MRI findings in Möbius syndrome: correlation with clinical features. Neurology 2000; 55(7): 1058-1060.

87 Ouanounou S, Saigal G, Birchansky S. Möbius syndrome. AJNR Am J Neuroradiol 2005; 26: 430-432.

88 Verzijl H, Valk J, de Vries R, Padberg GW. Radiologic evidence for absence of the facial nerve in Möbius syndrome. Neurology 2005; 64: 849-855. 